\title{
Multilevel Approach In Organizational Research: A Review Of Dual-Level Transformational Leadership
}

\author{
Amin Pourbarkhordari \\ Er Hua (Iris) Zhou \\ School of Management, \\ Huazhong University of Science and Technology, Wuhan, P.R.CHINA
}

Javad Pourkarimi

Faculty of Psychology \& Education, University of Tehran, Tehran, IRAN

doi: 10.19044/esj.2016.v12n4p445 URL:http://dx.doi.org/10.19044/esj.2016.v12n4p445

\begin{abstract}
Due to the nature of organizations as hierarchically nested systems, multilevel theoretical models are relevant to the vast majority of organizational phenomena; hence, the main purpose of this review was clarifying the importance of conceptualization and testing theories at multiple levels of analysis. By doing this, the current study added to the gloom by providing a comprehension literature review with explicit consideration of multilevel directed theory and measures in organizational studies. Specifically, this review answered call for deliberate distinction between individual and group levels of analysis in leadership research, in particular transformational leadership (TFL) which in recent years, based on well-grounded theory stating to multiple levels is scarce. Our multilevel approach in examining organizational phenomena at different levels corroborates the recommendation to investigate the impact of constructs and their relationships at multiple levels of analysis. Finally, two prominent measurement models which have been conducted to exhibit dual level transformational leadership behaviors were recommended.
\end{abstract}

Keywords: Multilevel Study, Transformational Leadership, Individual Level, Group Level

\section{Introduction}

Take into consideration of different levels in data analysis causes theoretical revolutions in science such as, biology (i.e. evolution happening at a higher level than the organism level), physics (i.e. operation of quantum mechanics at a level lower than the atomic level analysis) (Yammarino, Dionne, Uk Chun, \& Dansereau, 2005). However, given the nature of 
organizations as hierarchically nested systems, multilevel theoretical models are relevant to the vast majority of organizational phenomena and multilevel thinking has been growing among organizations' scholars (Hitt, Beamish, Jackson, \& Mathieu, 2007; Kozlowski \& Klein, 2000).

Organization as an integrated multilevel system consist of individuals and groups in which, each level includes different disciplines, theories, and approaches. In this realm, over the last two decades, academics are moving in the direction of an integrated conceptual framework for organizational science with considering the development of methodological paradigm (i.e. multilevel paradigm). This moving acts as a bridge for the micro-macro gap in theory and research in organizational science (Kozlowski \& Klein, 2000). Moreover, numerous academics have stated to avoid misleading of inference drawing, corresponding data analytic techniques and the measurement of constructs to the stated level(s) of analysis is very important; therefore, identifying the level(s) of analysis at which phenomena are assumed to exist in theory is necessary (Yammarino et al., 2005). Hitt et al. (2007) have argued that for an in-depth explanation of behaviors of individuals, groups, and organizations in the context where behaviors occur, researchers need to develop the theories and empirical investigations by using a multilevel lens. By doing this the fruitfulness of social behavior emerges and the multiple consequences of behavior across levels of social organization reveal. As Hitt et al. (2007) have cited, most developments in multilevel research were grounded in the 1980s, theoretically and analytically.

Moreover, social research as a domain in organizational studies refers to the relationship between individual and society in which, individuals interact with the social groups or may influenced by social contexts and in contrary, the properties of groups are influenced by the individuals who are belong to those groups. In this notion, groups and individuals defined at separate levels of a hierarchical system which social groups and individuals are conceptualized (Hox, 2010).

"Level" refers to the specific point in the organization's hierarchy, where a behavior observes (Avolio \& Bass, 1995); so that specification of different levels in organizational studies allows the scholars to examine the potential of theoretical misspecification prevalence; identification of levelsof-analysis issues has essential to theory building and without such levelsbased determination and without an explicit specification of multilevel analysis, understanding of a phenomena or concept may lead to the defective measures, incorrect data analyses and the invalid conclusions (Yammarino et al., 2005). It is apparent that failure to account for examining the relationships and respective constructs at appropriate level, cause effects misidentifications (Schriesheim, Castro, Zhou, \& DeChurch, 2006). Nevertheless, most previous management research examines organizational 
phenomena by investigating them at single levels of analysis. Therefore, since the management studies are growing, academics are advancing the understandings of phenomena by explicit attention to levels issues (Yammarino et al., 2005).

Based on above discussion, researchers can fully accomplish the theory building and respective hypothesis generation in organizational research with slow evolutionary change (Hitt et al., 2007) while, they include the lower and higher levels of analysis in their studies (Yammarino et al., 2005). Generally, the hierarchical systems can be drown at levels-based inferences with different hierarchical levels and often refer to the "multilevel research". In this kind of research some variables characterizing individuals and some variables characterizing groups; the variables can be measured at any level of analysis, while some of them may be directed at their 'own' natural level (Hox, 2010).

As we will show in this review, in the past decade, interest in the development of multilevel theoretical models in organizational studies has been increased dramatically; and as pointed out in the study of Yammarino et al. (2005), theoretical advancement, scale development and data analysis cannot be conducted accurately, if intended research fails to explicitly specify levels. However, only a small percentage of studies has been provided multilevel theoretical frameworks (Kozlowski \& Klein, 2000). To determine whether and where the hypotheses and constructs were employed effectively and the relationships between constructs truly occur we need to consider all within- and between-unit effects at the appropriate levels such as the individual level, the within-unit level and the between-unit level (Schriesheim et al., 2006). In addition, investigating of multilevel mediation processes is one of the advantages of multilevel models which is not simply hypothesized and empirically tested using normal statistical techniques (Zhang, Zyphur, \& Preacher, 2009).

Moreover, in this day and age, organizations principally have teambased structures (Braun, Peus, Weisweiler, \& Frey, 2013; Chen, Kirkman, Kanfer, Allen, \& Rosen, 2007); thus, to achieve the key objectives in current business practices, over the past decades researchers urged organizations seriously to rely on team-based structures (Cho \& Dansereau, 2010) and teams have become progressively more prevalent way of organizing work (Kozlowski \& Bell, 2003). In this regard and because of the growing teambased approaches in organizations and due to the role of capabilities of individuals in team performance, to fully understand the team leadership, we need to integrate the individual-level with group-level processes (Kozlowski \& Bell, 2003) and researchers are encouraged the managers and top leaders to considerate both individuals and teams as a whole (Braun et al., 2013; Chen et al., 2007). On the other hand, leading teams yields new challenges 
for leaders and organizations such as aligning shared mission and goals with individual goals and building a positive climate of trust and support (Braun et al., 2013; Wang \& Howell, 2010).

Apparently, multilevel approach in the leadership literature is relatively new and back to the last two decades ago. For instance, Bass (1990) called for well-grounded theory referring to multiple levels of leadership (Yammarino et al., 2005). In this realm, Avolio and Bass (1995) have argued that achieving a fully model of leadership, needs to study the leadership constructs from a behavior observed at individual, group or organization level over time. In similar vein, Yammarino et al. (2005) have cited that regardless of approach or realm to illustrate a comprehensive and integrative theory of leadership, fully incorporating multilevel analysis is necessary in all theory, measurement, data analysis and implication. Although, there is considerable emphasis in the prior organizational literature, especially in the research of leadership about multiple-level perspective (Yammarino et al., 2005) however, in previous models of leadership, the advancement of leadership constructs to different levels of analysis has received little attention (Avolio \& Bass, 1995).

Furthermore, seminal work of Bass (1985) about TFL has been considered in numerous researches and during the last decades is the most frequently researched topic in leadership studies (Yammarino et al., 2005) and in recent times, more scholars are interested in studying this particular leadership style due to the chief executives awareness of the ethical implications and authenticity importance in leadership processes (Jung, Yammarino, \& Lee, 2009). Besides, since transformational leaders inspire and motivate subordinates individually and collectively as a group, the theory of TFL suggests that this leadership style is related to the both subordinates and group or organization performance (Bass, 1985; Wang, Oh, Courtright, \& Colbert, 2011). Indeed, in traditional leadership models there is no clear distinction between leaders' interaction with their followers and leaders' interaction with teams (Wang \& Howell, 2012); whereas according to the TFL theories, transformational leaders influence followers at both individual and group levels (Bass, 1985). However, in prior TFL research there is the lack of explicit attention to distinguish between individual level and group level analysis and most prior research have examined the effect of TFL on either the individual followers or the whole team (Chun, Yammarino, Dionne, Sosik, \& Moon, 2009; Jung et al., 2009; Wang \& Howell, 2010; Wu, Tsui, \& Kinicki, 2010). Thus, researchers and practitioner have yet to consider individual level and group level simultaneously. Overwhelming this challenge necessitates capabilities of leaders in both individual and team leadership (Wang \& Howell, 2010). Therefore, in order to better understanding of TFL in contemporary 
organizations, this issue needs to be investigated at multi-level perspective (Cho \& Dansereau, 2010). Actually, failure to give sufficient attention to the multilevel analysis in organizational research and particularly in leadership studies has been criticized as a critical limitation and shortage (Schriesheim et al., 2006).

In view of the abovementioned discussion, our purpose here was to extend previous research and provide a comprehensive, narrative review of the literature to clarify the importance of conceptualization and testing theories at multiple levels of analysis with an explicit focus on levels-ofanalysis issues in TFL studies. Consequently, the present study contributes to this line of research in several ways. First, it sheds some light on the mechanisms through which organizational theory can be conceptualized and articulated. Second, the current study contributes to the study of TFL and unlike previous studies considering TFL as a single level analysis, this research focuses on multilevel perspective, answering Yammarino et al. (2005) and Wang and Howell (2010) call for expanding our understanding of specifically dual-level effect TFL through expanding the concept of TFL, at incorporating a multiple levels of analysis framework. We aim to fill this void by providing a brief summary of the evolution of multilevel research to encourage, promote, and support for multilevel research. Indeed, the present study try to show how the level-of-analysis and multilevel approach plays a fundamental and critical role in clarifying the relationships between variables and research hypothesized.

\section{Levels-of-Analysis issues in organizational studies}

In similar to the other disciplines such as psychology, education, and sociology, organizational behavior is a discipline with its own right in which the study of human activity related to the organizations at different levels is absolutely critical (Rousseau, 1985). In fact, increased bureaucratization and technological in current circumstance make organizations increasingly differentiated in both vertical and horizontal; so that the most management complications and problems root in multilevel phenomena (Hitt et al., 2007; Rousseau, 1985). Consequently, numerous calls in organizational studies give rise to emphasis on multi-level research to a more comprehensive understanding of organizational phenomena and to improve testing theoretical models (Rousseau, 1985; Yammarino \& Dubinsky, 1994). Thus, for organizational studies, multilevel approach is a natural significance of the establishment of organizational behavior (Rousseau, 1985). As Yammarino et al. (2005) have noted without appropriate multi-level techniques theoretical advancement that comprise organizational behavior necessitates approaches (Kozlowski \& Klein, 2000) cannot be conducted accurately and data analysis can lead to statistical deviations. Additionally, the trend of 
management studies progression during the past 30 years revealed that in spite of sensitivity to multilevel issues in theoretical development, measurement and analytical methods, researchers have to consider further development in these issues (Hitt et al., 2007) to get a meaningful understanding of the phenomena (Kozlowski \& Klein, 2000).

According to the definition, multilevel approaches are intended to associate micro and macro perspectives, identifying relationships between higher levels constructs on lower levels constructs. Consequently, a multilevel theoretical model identifies the top-down or bottom-up links between phenomena from diverse levels (Kozlowski \& Klein, 2000). In addition, due to the development organizational behavior as a dynamic social science phenomenon, organizational scientists are expected to using multilevel approaches to the study of phenomena (Rousseau, 1985). Therefore, researchers and practitioners must made an effort to outline the potential role of level in analytic models which would be valuable to help them understand the role of level issues and illuminates the multiple consequences in organizational research, in particular in organizational behavior (Rousseau, 1985).

The central theme in organizational studies is that individuals are embedded within groups, sequentially individuals are nested in departments or organizational units as groups nested within organizations, and organizations are nested in larger unit such as national or multinational organizations or industries and so on. In this domain, organizational entities are inherent in nested arrangements of numerous networks and inter organizational relationships. Therefore in these settings multilevel models have certain implications for scholars and practitioners (Hitt et al., 2007). Multilevel theories can explain multilevel problems in which there are a large number of possible direct effect and cross-level interactions. Accordingly, a multilevel theory can identify which variables belong to which level, and which direct effects and cross-level interaction effects can be expected (Hox, 2010).

Level of theory indicates the main level of generalizations which are expected to apply and level of measurement is a classification of the distinct unit that describes the nature of intended data which are assigned to the attributes for variables (Hitt et al., 2007). In this domain, one kind of boundary is designed to specify the different levels of analysis at which a theory is likely to hold (Yammarino \& Dubinsky, 1994). Accordingly, the level of analysis refers to the entities or objects of study which are included in theories (i.e., relationships among variables) and characteristically arranged in hierarchical order (i.e. higher levels (e.g., groups), lower levels (e.g., individuals), and lower levels are inserted in higher levels). In essence, levels of analysis are integral parts of the definitions of constructs, 
operationalization of measures, and empirical tests of theoretical associations (Yammarino \& Dubinsky, 1994). It means, the level of analysis points to the unit to which provided data and the relationship among variables are assigned for statistical analysis and hypothesis testing (Hitt et al., 2007; Rousseau, 1985). Generally, the level of analysis should be aligned with the level of theory to test hypotheses properly and successfully; therefore practically every researcher has confronted related challenges to select the appropriate level of analysis (Hitt et al., 2007). So, considering the level of theory and knowing the appropriate level of analysis that were assigned helps researcher to decide what methodologies are applied and helps them to decide how to interpret the results. In view of that, the level of measurement refers to the level at which data needed are collected to measure a given construct. Undoubtedly, individual level constructs be assessed with individual level data; on the other hand, group level constructs may be assessed with either individual level (in this case, individuals provide individual level data by ratings proposed variables which afterwards collected data combined to represent the unit as a whole) or group level data (Kozlowski \& Klein, 2000). Except from the above mentioned, research question should be aligned with provided data which have been matched the level of analysis of interest (Yammarino \& Dubinsky, 1994). It should be noted that the number of layers and nature of related levels are expected to vary from one study to another (Hitt et al., 2007) and depends to the nature of research theory.

In multilevel perspective the relationships between phenomena grounded at top-down or bottom-up processes (Kozlowski \& Klein, 2000) and different variables may come into a model at different levels (Rousseau, 1985). For example, to investigate the contextual effects, the influence of higher-level contextual elements on lower levels of the organizational system are described by top-down processes in which this action may be directed through a direct effect on lower-level units or moderating effect (Kozlowski \& Klein, 2000). In another instance, technology-structure compatibility effects on effectiveness at the subunit level while structure-environment fit may effects at higher levels (Rousseau, 1985).

Although, levels issues come into the research of organizational matters and bring different choice of measurement and analysis which relies on combining different organizational units, to avoid misspecification and aggregation biases in organizational theory and research, drawing accurate levels-based measurement and analysis are essential (Rousseau, 1985).

Population of a hierarchical structure is a potential problem of multilevel issue and according to the nature of constructs, variables may move from one level to another level through aggregation (i.e. moving the variables at a lower level to a higher level) or disaggregation (i.e. moving the 
variables at a higher level to a lower level) (Hox, 2010). The current challenge of multi-level research have emphasized on aggregation problems (Rousseau, 1985).

\section{Aggregation as a common procedure in multilevel analysis}

As we have discussed earlier, there is considerable emphasis in the prior literature of multilevel studies to considering the measurement model issue which requires basic ground rules and common procedure to state the variables aggregation which are measured at the lower-level and expected to represent at higher level. Bliese (2000) has highlighted that aggregating variables needs both theoretical and statistical support. Therefore, given that the individuals are nested within workgroups and validity of the construct at the measurement model is intended to be used in analyzing variables through examining patterns of within-group variance, prior to testing the hypotheses further analyses are required to be calculated via aggregation, most notably intra-class correlation (ICCs) and within group agreement (rwg).

\section{The $r_{w g}$ index}

$\mathrm{r}_{\mathrm{wg}}$ is a measure of agreement within groups and initially used to determine the appropriateness of aggregating data to higher levels of analysis (inter rater reliability) (James, Demaree, \& Wolf, 1984). This index refers to the irregular results of distributional properties of one's sample and provide accurate and interpretable estimates of rater agreement which allow researcher to control the response biases such as central tendency and social desirability (Biemann et al., 2012). $r_{w g}$ is a measure of inter rater agreement as unifying factor and procedure to justify aggregating individual perceptions to the proposed level of analysis (Biemann et al., 2012). formula:

The $r_{w g(j)}$ index is calculated for each group independently by below

Eq. (1):

$$
r_{w j(j)}=\frac{J\left[1-\left(\bar{s} x_{j}^{2} / \sigma_{\mathrm{E}}^{2}\right)\right]}{J\left[1-\left(\bar{s} x_{j}^{2} / \sigma_{\mathrm{E}}^{2}\right)\right]+\left(\bar{s} x_{j}^{2} / \sigma_{\mathrm{E}}^{2}\right)}
$$

Note: $r_{w g}(j)$ stands for the within-group agreement coefficient for mean scores based on J items; $\bar{s} x_{j}^{2}$ stands for the mean of the observed variances on the J items; $\sigma_{E}^{2}$ stands for the expected variance of a hypothesized null distribution (Castro, 2002; James et al., 1984, p. 88).

Moreover, James et al. (1984, pp. 85-94) have provided some initial conditions that should be met for using $r_{\mathrm{wg}}$ index such as: first, because of artificially low estimates of inter rater agreement in short response format (e.g., a 2-point scale) it should be used with distinct response formats (e.g., a 
5- or 7-point scale); second, researcher should employ measures that "have acceptable psychometric properties" with almost equal-interval measurement; third, it needs empirical evidence to supports the null distribution; forth, the distribution of collected responses cannot be multimodal or bimodal (Castro, 2002); as a final point, it was intended to be used to measures with 'essentially parallel' indicators of the same construct'” (James et al., 1984, p. 88), indicating that the measure should be unidimensional (Castro, 2002).

Biemann et al. (2012) have suggested that within-group agreement ( $\mathrm{r}_{\mathrm{wg}}$ values) above the conventional acceptable value of 0.7 can be sufficient to support the aggregation to the group level for variables. Since the agreement is tested for each shared property measure of each unit, the high values of $r_{w g}$ for intended variables provide empirical support for inter-rater agreement within the unit. However, because $r_{w g}$ values could potentially overestimate within group agreement and to further justify aggregation to the group level, we need to conduct additional analyses regarding the validity of these shared variables following suggestions by Bliese (2000).

\section{Intraclass correlation coefficients (ICCs)}

In essence, we calculated interclass correlation coefficients ICC (1) and ICC (2) to investigate whether average scores differed considerably across groups. ICCs values were based on a one-way analysis of variance (ANOVA) which ICC (1) gives an estimate of the extent to which individual-level variability on a given measure is explained by higher-level units and refers to the proportion of the total variance that can be explained by group membership. The ICC (2) provides an estimate of the reliability of overall sample or group means which is naturally estimated with the use of mean squares from one way random-effects ANOVA (Bliese, 2000). In view of that, ICCs examine inter rater reliability for each shared property across the sample and according to the consistency-based approaches, they evaluate between-group variance which is considered in relation to the total (between and within) variance (Kozlowski \& Klein, 2000).

Indeed, ICCs are applied to evaluate group-level properties of data when the aim of study is finding the relationship among variables of a common class in which variables share both their metric and variance (Castro, 2002). ICC (1) depicts the aggregate of variance in individual level responses that can be explained by group membership (i.e. estimates the ratio of between-group variance to total variance) which is not affected by group size or by the number of groups. ICC (2) index estimates the group-mean reliability (internal consistency) of the group means in a sample (Bliese, 2000).

ICCs are calculated as following equations: 
Eq. (2):

$$
\operatorname{ICC}(1)=\left(\mathrm{ms}_{\mathrm{b}}-\mathrm{ms}_{\mathrm{w}}\right) /\left[\mathrm{ms}_{\mathrm{b}}+\left(\left(n_{\mathrm{g}}-1\right) \mathrm{ms}_{\mathrm{w}}\right)\right]
$$

Note: $m s_{b}$ stands for the between-group mean square; $m s_{w}$ stands for the within-group mean square and $n_{g}$ stands for the group size.

$$
\mathrm{ICC}(2)=\left(\mathrm{ms}_{\mathrm{b}}-\mathrm{ms}_{\mathrm{w}}\right) / \mathrm{ms}_{\mathrm{b}}
$$

Meanwhile, Bliese (2000) has noted that when the group size is large, ICC (2) has conjunction with the ICC (1) and group size, thus it is expected to be calculated using the Spearman-Brown formula as following equation:

$$
\text { Eq. (4): }
$$

$$
\operatorname{ICC}(2)=\left[n_{g} \times \operatorname{ICC}(1)\right] /\left[1+\left(n_{g}-1\right) \times \operatorname{ICC}(1)\right]
$$

Actually, large group sizes cause to have more stable mean scores and consequently we expected to get high ICC (2) values and low ICC (1) values. However, in both above mentioned equations we assume equal group sizes (Castro, 2002).

The assumptions of analysis of variance (ANOVA) are subjected to these indexes due to the variance apportioning based of ICCs. These assumptions includes homogeneity of units variance; normality of distributed scores, statistical independence of observations and equal psychological intervals of measures (Castro, 2002). Even though there is no absolute standard value for ICCs, an equal to or greater than 0.05 (Bliese, 2000) indicate that participants from the same work unit responded in a more similar way than those from different work units.

Briefly, the $\mathrm{r}_{\mathrm{wg}}$, ICC (1), and ICC (2) values measure group-level properties of data and will justify the aggregation of the data in which support the appropriateness of aggregating the group-level variables and reflect our conceptualization of the constructs as the group characteristic. ICCs apply to across all groups whereas the $r_{w g}$ applies to each group separately and it is not useful to estimate interaction terms or two or more predictors at the same time (Castro, 2002).

\section{Multilevel approach in transformational leadership}

According to the Yammarino and Dubinsky (1994) arguments about theoretical models in organizational studies, a well formulated research theory covers variables, relationships, and the boundaries or domains of that theory. Moreover, since most managerial issues such as connections between firm strategies and firm performance interactions between leaders and employees, leadership behaviors and incentive programs which involve social dynamics inference are too complex; conducting respective research is likely to require incorporation of multiple levels of analysis and the integration of insights from macro and micro level (Hitt et al., 2007). As specified in the quotation from Yammarino et al. (2005) and Chun et al. (2009) leadership phenomena which could occurs between followers and 
respective leaders, between groups and respective leaders, and even between multiple groups of followers in an organization (i.e. theoretically these relationships can construct differently as stated by differences between groups, differences within groups and differences between followers and respective group independently) is fundamentally multiple-level phenomenon in nature where there are several plausible levels of analysis (Biemann et al., 2012; Schriesheim et al., 2006) and this approach to see leadership at various levels has obtained increasing importance (Chen et al., 2007; Chun et al., 2009; Wang \& Howell, 2010, 2012; Yammarino, 1990; Yammarino \& Bass, 1990; Yammarino \& Dansereau, 2008; Yammarino et al., 2005; Yammarino \& Dubinsky, 1994). Also, since the individuals are nested in the group as a meaningful entity, considering individual values on the theoretical construct relative to the group value is informative and necessary for interpreting an individual's situation (Braun et al., 2013). Consequently, accumulating evidence suggests that leader behavior engage not only in particular individuals but also engage in a group in which leaders may exhibit similar behaviors towards individuals who are working at the same group (Avolio, Zhu, Koh, \& Bhatia, 2004). In organizational leadership studies the level of analysis at which leadership processes and associations are likely to hold and operate is a key issue (Yammarino \& Dansereau, 2008) and provides a more comprehensive understanding of leadership (Breevaart et al., 2014). However, there is a dearth of knowledge in level of analysis issues in both theoretical and empirical studies of leadership (Braun et al., 2013; Yammarino et al., 2005) and limited conceptual work of multilevel perspective in organizational leadership studies exists (Yammarino \& Dubinsky, 1994).

Quit possibly, to date, TFL theory is the most influential leadership theory is the most researched leadership concept (Braun et al., 2013). In respect to the social processes, transformational leaders inspire their followers to high levels of collective satisfaction along with conveying and articulating a strong sense of mission and vision and raise subordinates' social identification on their belonging to the group. Consequently, this social identification extends respect, trust, pride and loyalty among subordinates which can motivate them to work together with more intensive exchange and contribution (Ling, Simsek, Lubatkin, \& Veiga, 2008). Furthermore, the original TFL theories highlighted the direct influence of leaders on followers in which a leader may treat their each follower by different behaviors (Bass, 1985; Burns, 1978) whereas some studies proposed that TFL behaviors are engaged to the whole group as a shared perception among followers (Wang \& Howell, 2010). For instance, according to the Yammarino et al. (2005) quotation, TFL is primarily conceptualized, measured, and asserted in terms of individual differences 
(Jung et al., 2009). Additionally, Schriesheim et al. (2006) based on theory of House (1996) have expected that an effect can be manifested at both the within-group and the between-group levels in which work groups do not influence upon the relationships. In this vein, leadership researchers propose TFL theory as an unbounded theory (Bass, 1985, 1990) and in line with above discussion about multilevel perspective importance in leadership phenomena and due to the widespread move to multilevel studies, there is convincing evidence that TFL is a multilevel phenomenon which can be manifested the functional characteristics at both individual and group levels simultaneously (Avolio \& Bass, 1995; Charbonnier-Voirin, El Akremi, \& Vandenberghe, 2010; Cho \& Dansereau, 2010; Jung et al., 2009; Liao \& Chuang, 2007; To, Tse, \& Ashkanasy, 2015). According to the Bass (1985) transformational leaders not only make the meaning and challenge of the work clear for followers but also give them high levels of confidence through increasing group spirit. Therefore, this transformation processes reflect maintaining the individuals' tendency toward a collective-level direction and motivating individuals to work harder and put more efforts to get the collective goals and benefits (Cho \& Dansereau, 2010). This kind of theory is expected to hold in various fields of study and numerous events at different time; it can be hold at different levels of analysis and can be implicated at across different cultures and national boundaries (Yammarino \& Dubinsky, 1994).

Specifically, transformational leaders enable and stimulate their followers intellectually by giving more autonomy and providing a sense of responsibility to the followers; also these leaders pay more attention to individual needs of their followers to increase individuals' willingness to take responsibility individually and advance their self-management and selfdevelopment skills through indirect supervision. Clearly, leaders by having these behaviors not only empower individuals but also raise their perceptions as a group member (Ling et al., 2008). Furthermore, in respect of task processes, followers who percept that their leaders has transformational behavior, may solve their problems in various ways (Bass, 1985) in which this diversity of perspectives to view the problems and difficulties help groups to take part in decision making process actively through emphasizing the importance of teamwork in performing collective tasks (Ling et al., 2008).

However, in spite of the existing numerous calls for deliberate differentiation between individual and group levels of analysis in TFL research (Bass, 1985, 1990; Burns, 1978; Yammarino \& Dubinsky, 1994) these calls generally are limited and theorizing and testing the levels of analysis at which TFL operates has been neglected in respective studies (Braun et al., 2013; Cho \& Dansereau, 2010; Wang \& Howell, 2010; 
Yammarino et al., 2005). Definitely, there is no consensus about whether TFL is an individual- or a group-level phenomenon (Wang \& Howell, 2010; Wu et al., 2010) and just a few empirical studies correctly applied multilevel perspective. Kozlowski and Bell (2003) have cited if researchers fail to integrate individual-level processes with group-level processes, their understanding of effective leadership would be limited.

Accordingly and with the aim of fill this gap recently, Chen et al. (2007); Wu et al. (2010) and Wang and Howell (2010) provide compelling evidence to study TFL phenomena through multilevel analysis. They have been attempted to help leaders and practitioners to fully understand the dynamic interactions and relationships between the individuals within a group and the group as a whole (To et al., 2015). For example, Wu et al. (2010) defined differentiated leadership in their study to investigate the dual level TFL effect on followers as the extent to which a leader displays varying levels of individual-focused behavior across diverse group members. They reported that leaders who recognize and support both individual and group needs may unintentionally come to meet the group outcomes. Similarly, Wang and Howell (2012) have argued that, transformational leaders not only develop followers' competencies (i.e. as the individual-focused behavior) but also they supports shared commitment to group goals and construct positive group processes (i.e. as the group focused behavior). Studying the TFL behaviors at two different levels provided the groundwork for multilevel TFL studies (Wang \& Howell, 2010). In another study Chen et al. (2007) conducted a study of empowering leadership and concluded that leaders can perform to both their individual members and group at the same time and they signified an important step toward understanding leadership in the group setting by highlighting the dynamic which interplay between the individuals within a group and the group as a whole.

In consistence with previous research (Bass, 1990; Yammarino \& Bass, 1990), Yammarino and Dubinsky (1994) have been highlighted three different levels for investigating the behavior of leaders such as: individuals as a person either followers or leaders who respond independently; Groups as a collective of individuals who act together and interact with one another and report to a shared direct leader. Dyads, as a special case of groups consist of two individuals who have interdependent relationships within a work group. Likewise, Schriesheim et al. (2006) have noted that some leaders treat their followers with same behavior in the direction of the whole followers as a group whereas the other leaders may treat their followers differently one to one but still perform a special style within work group. Thus, they concluded that the leader-follower relationships could be different between groups while the interactions between leader-follower could be homogeneous within each group and on the other hand leaders may 
treat each subordinate within the group by different behaviors. This situation has been demonstrated a diversity in leader-follower relationships within groups as a within-group phenomenon. Moreover, the most of the leadership studies which performed at multilevel analysis collect the survey data just from individuals and for group variables aggregate those data to assert at the group level; in other words, a group level measure is achieved through averaging followers' assessments (Biemann et al., 2012).

Another point in levels of analysis issue in the leadership studies is cross level effect. As Wang and Howell (2012) have been conducted in their study individual- and group-level TFL processes are not independent rather both levels can connected to each other through cross-level effects. A crosslevel effect refers to the effect of a variable in the group-level TFL process on another variable or on a relationship in the individual-level TFL process. Accordingly, Avolio and Bass (1995) have proposed that to accurate measure of TFL, researchers should use a "cross-level" model in study measurements and explanation of TFL. Generally, the exertion of cross-level effects has been neglected to this area of research in particular to the leadership and work group research.

\section{Definition of individual level \& group level transformational leadership}

Individual differences in responses of subordinates is a potential boundary condition on TFL theory in which individual variability of attributions, and/or cognitive categorizations and leader-follower relationships emerge (Yammarino \& Dubinsky, 1994). Furthermore, in theory of transformational/ charismatic leadership several researchers such as Bass (1985, 1990) and House (1996) have emphasized the role of leader behaviors, personality characteristics and individual follower reactions. The general concept at individual level is that transformational leaders' behaviors are independent which can be perceived as unique behavior by each follower. Thus, the nature of follower-leader relationships is differences within groups and leaders may display different styles to their subordinates. At the individual level Wang and Howell (2012) have noted that individualfocused TFL behavior raise leader identification which in turn, improve followers' self-efficacy, loyalty and commitment.

A transformational leader by demonstrating individual-focused TFL behavior can encourage their subordinates to identify with him or her and recognize the uniqueness of each subordinate's ability and skill (Jung et al., 2009). Consequently, respective subordinates are more willing to communicate with leaders bay mutual trust, support, and satisfaction to identify with the leader who is concerned about the growth and welfare of each follower (Wang \& Howell, 2012). At the individual level of analysis of TFL, the interaction between leaders and their subordinates is defined based 
on the each subordinate's perception about respective leader's behaviors in which work groups has no practical effect on individuals (Schriesheim et al., 2006). Thus, leaders may justify their subordinates' actions and behaviors according to the follower's perspective. In this notion, the leader's perspective and following behavior is transformed by recognizing their subordinate differences in needs and inspiring and empowering them to achieve higher levels of performance (Avolio \& Bass, 1995; Bass, 1985; Bass \& Avolio, 1994). Furthermore, the assumption underlying the individual level is that leaders exhibit a different style toward each subordinate and relationship between leader and followers is established on a one-to-one basis within a group in which the leaders' style and interactions are different within the group or across dyads (heterogeneous leader-follower interactions). This approach has been tagged as the leader-member exchange (LMX) approach or a group parts model (Yammarino \& Bass, 1990). In this vein and due to supporting the argument of dual effect of TFL, Wang and Howell (2010, p. 1135) defined "individual-focused TFL behavior as a behavior aiming to empower individual followers to develop their full potential, enhance their abilities and skills, and improve their self-efficacy and self-esteem”. According to the this definition, transformational leaders develop their subordinates' potential abilities, skills, and self-efficacy by providing their followers with customized coaching and mentoring (Wang \& Howell, 2010). These leaders understand individual followers' unique characteristics, abilities and needs; and according to the experiences and abilities of each follower, arrange different goals and provide different coaching way. By doing this, leaders have various behavior across followers (Wang \& Howell, 2012).

In addition, Yammarino and Bass (1990) have presented another perspective regard to the individual level for leader-follower relationships as the information-processing approach. In this case, interactions between a leader and their followers depend on how each follower cognitively interprets the leaders' behavior, their relationships are based on individual differences and leader-follower interactions are individualized. Accordingly, due to the leaders' characteristics, a leader may stimulate "love" in some followers while he/she can engender "hate" in other followers and some followers of a group might have a favorable relationship with their leader, while other followers of that group might have a less favorable relationship. In this view, associations among the TFL dimensions and leaders' effectiveness might be based on individual information processing (Bass, 1985; Yammarino \& Bass, 1990).

In the instance of individual-focused TFL, leaders provide individualized support to each follower through coaching and empowering them to their full potential as well as changing each follower's problem 
awareness based on their intellectual capabilities by challenging current ways (To et al., 2015; Tse \& Chiu, 2014; Wu et al., 2010). These attributions of TFL determines interpersonal and within-person processes and outcomes in organization (To et al., 2015). Wu et al. (2010) have claimed that Individual-focused leadership is grounded in situational leadership theories and LMX theory to show the differentiate leaders' behavior is on the basis of follower's individual differences (e.g., abilities) and contextual factors (e.g., resources, task structure). In this domain, they have adopted the label differentiated leadership to refer the extent to which a leader exhibits varying levels of individual-focused leadership behavior across different group members.

On the other hand, according to the Avolio and Bass (1995) study, transformational leader behaviors have been directed at unit members as a whole by creating group norms which cause more focus on developing subordinates' potential and encouraging them to help their colleagues constantly. Subsequently, due to the vast span of influence of leaders, these norms will become part of organizational cultures (Avolio \& Bass, 1995). TFL at the group level addresses the importance of group goals and rises the shared values and beliefs among followers by treating all members with similar behavior, articulating the same group vision and emphasizing the same shared group identity to all members (Wang \& Howell, 2012). Afterwards, followers are more willing to find the opportunities for increasing their contribution in their group when they sacrifice their own interests towards to the group's interests (Cho \& Dansereau, 2010). Moreover, leaders after setting the shared goals for group may encourage followers to work together and express confidence of group goal achievement (Wang \& Howell, 2012); this group goals success is rooted in the improved levels of social identification as a characteristic of followers of transformational leaders (Wang et al., 2011). Consequently, leaders through leading to higher levels of group potency and encouraging higher levels of group cohesion (Bass, Avolio, Jung, \& Berson, 2003) assist harmonization and collaboration among group members (Wang et al., 2011).

Wang and Howell (2010, p. 1135) defined "group-focused TFL behavior as behavior aiming to communicate the importance of group goals, develop shared values and beliefs, and inspire unified effort to achieve group goals”. The influence target in this case is a whole group rather than group members within the group; to put it simply, all individual members percept their group leader's behavior similar and shared within their group (Yammarino \& Bass, 1990). In this regard and in contrast to individualfocused TFL, group-focused TFL behaviors might articulate a new compelling vision and communicate it to the whole group; inspire all group members to internalize the new vision as part of their beliefs and values, and 
also define themselves based on the group's success and identity (To et al., 2015; Tse \& Chiu, 2014; Wu et al., 2010).

As indicated in the quotation from Wang and Howell (2012) and Wu et al. (2010) at the group level in which the leader's behavior is embedded, transformational leaders activate followers' collective self, elicit group identification and lead to shared perceptions which boost their collective efficacy and group cohesiveness, followers likely have more collective belief about their group success. Transformational leaders provide direction for the group through delivering speeches to the group and group-based rewards (Wu et al., 2010). Additionally, transformational leaders can improve group performance through emphasizing the shared values and group members' characteristics, inspiring their subordinates to sacrifice their own interests for the collective purpose of the group, and extend mutual trust and collaboration among group members (Bass, 1985). Therefore, when a leader focuses on group transformational behaviors, they might be perceived as a role and representative model of the group who their followers recognize him/ she as an effective leader (Wang \& Howell, 2012).

Moreover, TFL as a participative leadership style gives emphasis to each group member as equally important and gives rise to the influences of group perceptions of related leaders on group's outcomes by conducting shared mental model convergence (Braun et al., 2013). Wang and Howell (2010) have argued, to drive team performance effectively individual members should have the skills and abilities to complete their job and in order to perform well as a whole need to trust and support each other (Wang \& Howell, 2010). In this domain, group-level TFL is a form of ambient stimulus among work group members which display an overall pattern of leadership behaviors to the entire work group (Liao \& Chuang, 2007; Peng Wang \& Weichun Zhu, 2011) in which Chen et al. (2007, p. 333) conceptualized the group level of TFL as "a climate variable that is shared among all team members”.

Yammarino and Bass (1990) have demonstrated another perspective regard to the group level for leader-follower relationships as the average leadership style (ALS) approach. In this approach, interactions between a leader and their followers are based on a similar style toward an entire group of followers and although the relationships with followers are different across leaders, there is no difference within groups in leader-follower relationships (homogeneous leader-follower interactions). Accordingly, all followers in a group may have a favorable relationship with their leader, whereas followers of another group may have a less favorable relationship with that leader. In this notion, associations among the TFL dimensions (i.e. charisma, inspirational leadership, and leaders' effectiveness) might be based on a whole groups (Bass, 1985; Yammarino \& Bass, 1990). Yammarino and 
Dubinsky (1994) have noted that, to evaluate leader-follower interactions some components and various outcomes in TFL theory which have been operationalized by Bass and Avolio (1994); Yammarino and Bass (1990) such as leader effectiveness, subordinate extra effort, subordinate satisfaction with the leader need to be constructed at more than one level of analysis (Yammarino \& Dubinsky, 1994).

\section{Dimensions of dual level transformational leadership}

Similar to other constructs, in the measurement arena, to represent more accurately TFL phenomena at the organization, group, and individual levels, researchers need to develop conceptually similar, but different, measures or items with respect to the level of analysis at which the construct is being applied (Avolio \& Bass, 1995); measurements must include the referent (entities or levels of analysis) explicitly (Yammarino et al., 2005). Moreover, since previous TFL studies have opted to use a global measure of TFL that does not distinguish between individual and group level TFL measures (Wang \& Howell, 2010) a central tenet of this study was providing an explicit consideration of individual- and group-directed measures of transformational leader behavior. In this regard, therefore, we presented two prominent measurement models which have been adapted recently and have been cited in most recent publications as the strongest components with high predictability for leadership effectiveness as follow:

Kark and Shamir (2002) through a theoretical development study suggested a dual-level model that distinguishes TFL behaviors into the individual level and the group level. Drawing on their model, they have claimed that two TFL dimensions-individualized consideration and intellectual stimulation- appear to focus on individual followers' needs and capabilities and are expected to establish a strong relation between the leader and each follower. Thus, they are more likely to be demonstrated at the individual level. Individualized consideration refers to the behaviors that leaders focus on particular needs and expectations for each individual follower and provides individualized support for the development of the follower (Bass, 1985). Kark and Shamir (2002, p. 82) have noted that this behavior stresses the "distinctiveness of each follower and the unique relationship between the leader and each follower”. Intellectual stimulation refers to leadership behaviors that encourage individual followers to find innovative and creative solutions to their problems through arising and changing followers' problem awareness, thoughts, imagination, beliefs, and values (Bass, 1985). Respectively, the other two TFL dimensions-idealized influence and inspirational motivation - appear to focus on the identity of the group due to their emphasis on collective efforts, shared values and collective goals. Idealized influence which is known as charisma refers to 
leaders' behaviors that reflect articulating a vision of the future and group identity through highlighting the shared interests and values among members, and highlighting the uniqueness of the group (Wu et al., 2010). Inspirational motivation refers to leadership behaviors that focus on all connections of leaders with their follower group as a whole rather than with individual followers to achieve a collective vision by requesting the involvement and collective effort of all employees (Wu et al., 2010), emphasizing collective identities and expressing confidence in their followers (Cho \& Dansereau, 2010).

Since the aforementioned model and similar studies that conducted to establish a multilevel measurement of TFL construct, used the Multifactor Leadership Questionnaire (MLQ; Avolio et al., 2004) which has ambiguous items that do not distinguish between levels of analysis and might not be an appropriate scale to measure multilevel TFL; Wang and Howell (2010) have been designed an accurate dual-level TFL scale thorough a deductive approach to measure individual-focused behavior at the individual level and group-focused behavior at the group level. They have validated the scale using a sample of 203 members from 60 work groups in a Canadian company with an appropriate referent for each item to ensure that the level of the theory and the level of the measure align.

Drawing on the theoretical definitions of individual- and groupfocused TFL behavior Wang and Howell (2010, pp. 1135-1136) developed a dual-level TFL scale that identifies four individual-focused TFL dimensions and three group-focused TFL dimensions to investigate the diverse effects of these dual-level behaviors on followers at the individual and group levels of analysis, simultaneously.

Individual-focused TFL dimensions: (a) communicating high expectations: based on inspirational motivation in Bass (1985) TFL theory is defined as behavior that exhibits the leader's expectations for excellence, quality, and high performance in his or her followers; (b) follower development: derived from individualized consideration in Bass (1985) TFL theory is defined as behavior that develops followers' skills and abilities; (c) intellectual stimulation: is defined as stimulating followers to be creative by questioning assumptions, viewing the problems from different angles, managing challenges in different ways and encourage followers to come up with new and better ways of working; (d) personal recognition: originated from contingent reward in Bass (1985) TFL theory is defined as praising and acknowledging followers for achieving specified goals or discovering new approaches.

Group-focused TFL dimensions: (a) emphasizing group identity: evident in idealized influence in Bass (1985) TFL theory is defined as underlining shared characteristics among group members, highlighting the 
uniqueness of the group and emphasizing followers' membership in the group; (b) communicating a group vision: aligned with inspirational motivation in Bass (1985) TFL theory refers to behaviors that inspire followers to share the leader's vision of the group, and as such articulate an idealized and attractive picture of the future of the group; (c) team building: refers to the behavior that emphasize on promoting cooperation, resolving frictions, and facilitating mutual trust among followers through assigning team goals, rewarding followers according to the team achievements, and facilitating social interactions among group members (Wang \& Howell, 2010).

\section{Conclusion}

Since, there is a solid theoretical groundwork for an applicable levels perspective, in the current study we demonstrated a comprehensive literature review to exhibit how multilevel research which addresses the levels of theory, measurement, and analysis might improve our understanding of how organizational phenomena are related to different outcomes. Specifically, in spite of ignoring levels-of-analysis issues in previous studies, we drew academics' attention to this subject and concluded that researchers and practitioners should use different strategies to analysis interactions between organizational phenomena at various levels such as individually, group as a whole or organization.

Another contribution and purpose of this paper was to extend previous leadership research by providing a conceptual clarification of TFL through underlying the leader-follower interactions in terms of multiple levels of analysis. In spite of the substantial research on the leadership phenomenon from a multilevel perspective; however, the existence literature provides little guidance for researchers in this issue. Therefore, further research has yet to systematically consider at least the top-down as well as bottom-up interactions of two levels. Accordingly, this literature review study provided enough support that the study of TFL theory is most appropriate for applying multilevel analysis framework. Indeed, researchers for studying leadership behavior need to consider at least two levels of analysis whereas most prior studying in this area of research have mainly focused on one level of analysis. Ultimately, we attempted to address the ambiguity about levels of analysis in TFL measures by providing an explicit consideration of individual- and group-directed measures of transformational leader behavior. Subsequently, two prominent dual-level TFL scales in which all items in the second scale have a level-specific referent to ensure that the levels of the collected data align with the theory under study were presented. This multilevel approach corroborates the recommendation of extending the application of multiple levels of analysis for advancement 
toward the development of more influential analytic tools; thus, it is inevitable that researchers must explicitly advocate a multi-level approach in their studies and upcoming experimental research should determine relationships between variables through multilevel perspective.

\section{References:}

Avolio, B. J., \& Bass, B. M. (1995). Individual consideration viewed at multiple levels of analysis: A multi-level framework for examining the diffusion of transformational leadership. The Leadership Quarterly, 6(2), 199-218. http://dx.doi.org/10.1016/1048-9843(95)90035-7

Avolio, B. J., Zhu, W., Koh, W., \& Bhatia, P. (2004). Transformational leadership and organizational commitment: mediating role of psychological empowerment and moderating role of structural distance. Journal of organizational Behavior, 25(8), 951-968. http://dx.doi.org/10.1002/job.283

Bass, B. M. (1985). Leadership and performance beyond expectations: Collier Macmillan. New York: The Free Press.

Bass, B. M. (1990). From transactional to transformational leadership: Learning to share the vision. Organizational Dynamics, 19-31.

Bass, B. M., \& Avolio, B. J. (1994). Transformational Leadership And Organizational Culture. International Journal of Public Administration, 17(3-4), 541-554. http://dx.doi.org/10.1080/01900699408524907

Bass, B. M., Avolio, B. J., Jung, D. I., \& Berson, Y. (2003). Predicting unit performance by assessing transformational and transactional leadership. Journal of Applied Psychology, 88(2), 207-218.

Biemann, T., Cole, M. S., \& Voelpel, S. (2012). Within-group agreement: On the use (and misuse) of rWG and rWG(J) in leadership research and some best practice guidelines. The Leadership Quarterly, 23(1), 66-80. http://dx.doi.org/10.1016/j.leaqua.2011.11.006

Bliese, P. D. (2000). Within-group agreement, non-independence, and reliability: Implications for data aggregation and analysis.

Braun, S., Peus, C., Weisweiler, S., \& Frey, D. (2013). Transformational leadership, job satisfaction, and team performance: A multilevel mediation model of trust. The Leadership Quarterly, 24(1), 270-283. http://dx.doi.org/10.1016/j.leaqua.2012.11.006

Breevaart, K., Bakker, A., Hetland, J., Demerouti, E., Olsen, O. K., \& Espevik, R. (2014). Daily transactional and transformational leadership and daily employee engagement. Journal of Occupational and Organizational Psychology, 87(1), 138-157. http://dx.doi.org/10.1111/joop.12041

Burns, J. M. (1978). Leadership: New Yorker: Harper \& Row.

Castro, S. L. (2002). Data analytic methods for the analysis of multilevel questions: A comparison of intraclass correlation coefficients, rwg(j), hierarchical linear modeling, within- and between-analysis, and random 
group resampling. The Leadership Quarterly, 13(1), 69-93. http://dx.doi.org/10.1016/S1048-9843(01)00105-9

Charbonnier-Voirin, A., El Akremi, A., \& Vandenberghe, C. (2010). A Multilevel Model of Transformational Leadership and Adaptive Performance and the Moderating Role of Climate for Innovation. Group \& Organization Management, 35(6), 699-726. doi: 10.1177/1059601110390833

Chen, G., Kirkman, B. L., Kanfer, R., Allen, D., \& Rosen, B. (2007). A multilevel study of leadership, empowerment, and performance in teams. Journal of Applied Psychology, 92(2), 331-346. doi: http://psycnet.apa.org/doi/10.1037/0021-9010.92.2.331

Cho, J., \& Dansereau, F. (2010). Are transformational leaders fair? A multilevel study of transformational leadership, justice perceptions, and organizational citizenship behaviors. The Leadership Quarterly, 21(3), 409421. doi: http://dx.doi.org/10.1016/j.leaqua.2010.03.006

Chun, J. U., Yammarino, F. J., Dionne, S. D., Sosik, J. J., \& Moon, H. K. (2009). Leadership across hierarchical levels: Multiple levels of management and multiple levels of analysis. The Leadership Quarterly, 20(5), 689-707. doi: http://dx.doi.org/10.1016/j.leaqua.2009.06.003

Hitt, M. A., Beamish, P. W., Jackson, S. E., \& Mathieu, J. E. (2007). Building theoretical and empirical bridges across levels: Multilevel research in management. Academy of Management Journal, 50(6), 1385-1399.

House, R. J. (1996). Path-goal theory of leadership: Lessons, legacy, and a reformulated theory. The Leadership Quarterly, 7, 323-352.

Hox, J. (2010). Multilevel analysis: Techniques and applications: Routledge. James, L. R., Demaree, R. G., \& Wolf, G. (1984). Estimating within-group interrater reliability with and without response bias. Journal of Applied Psychology, 69(1), 85-98. doi: http://dx.doi.org/10.1037/0021-9010.69.1.85

Jung, D., Yammarino, F. J., \& Lee, J. K. (2009). Moderating role of subordinates' attitudes on transformational leadership and effectiveness: A multi-cultural and multi-level perspective. The Leadership Quarterly, 20(4), 586-603. doi: http://dx.doi.org/10.1016/j.leaqua.2009.04.011

Kark, R., \& Shamir, B. (2002). The Dual Effect of Transformational Leadership: Priming Relational and Collective Selves and Further Effects on Followers. In B. J. Avolio \& F. J. Yammarino (Eds.), Transformational and Charismatic Leadership: The road ahead (Vol. 2, pp. 67-91). Amsterdam, the Netherlands: JAI Press.

Kozlowski, S. W. J., \& Bell, B. S. (2003). Work groups and teams in organizations. InW. C. Borman, DA Ilgen, RJ Klimoski,(Eds.), Handbook of psychology: Vol. 12 Industrial and organizational psychology (pp. 333-375). New York: John Wiley \& Sons, Inc.

Kozlowski, S. W. J., \& Klein, K. J. (2000). A multilevel approach to theory and research in organizations: Contextual, temporal, and emergent processes. 
In K. J. Klein \& S. W. J. Kozlowski (Eds.) Multilevel theory, research and methods in organizations: Foundations, extensions, and new directions (pp. 3-90): San Francisco, CA: Jossey-Bass.

Liao, H., \& Chuang, A. (2007). Transforming service employees and climate: a multilevel, multisource examination of transformational leadership in building long-term service relationships. Journal of Applied Psychology, 92(4), 1006-1019. doi: http://psycnet.apa.org/doi/10.1037/00219010.92.4.1006

Ling, Y., Simsek, Z., Lubatkin, M. H., \& Veiga, J. F. (2008). Transformational Leadership's Role in Promoting Corporate Entrepreneurship: Examining the CEO-TMT Interface. Academy of Management Journal, 51(3), 557-576. doi: 10.5465/amj.2008.32626023

Peng Wang, \& Weichun Zhu. (2011). Mediating Role of Creative Identity in the Influence of Transformational Leadership on Creativity: Is There a Multilevel Effect? Journal of Leadership \& Organizational Studies, 18(1), 25-39. doi: 10.1177/1548051810368549

Rousseau, D. M. (1985). Issues of level in organizational research: Multilevel and cross-level perspectives. Research in organizational behavior, 7(1), 1-37.

Schriesheim, C. A., Castro, S. L., Zhou, X., \& DeChurch, L. A. (2006). An investigation of path-goal and transformational leadership theory predictions at the individual level of analysis. The Leadership Quarterly, 17(1), 21-38. doi: http://dx.doi.org/10.1016/j.leaqua.2005.10.008

To, M. L., Tse, H. H. M., \& Ashkanasy, N. M. (2015). A multilevel model of transformational leadership, affect, and creative process behavior in work teams. The Leadership Quarterly, 26(4), 543-556. doi: http://dx.doi.org/10.1016/j.leaqua.2015.05.005

Tse, H. H. M., \& Chiu, W. C. K. (2014). Transformational leadership and job performance: A social identity perspective. Journal of Business Research, 67(1), 2827-2835. http://dx.doi.org/10.1016/j.jbusres.2012.07.018 Wang, G., Oh, I.-S., Courtright, S. H., \& Colbert, A. E. (2011). Transformational leadership and performance across criteria and levels: A meta-analytic review of 25 years of research. Group \& Organization Management, 36(2), 223-270.

Wang, X.-H., \& Howell, J. M. (2010). Exploring the dual-level effects of transformational leadership on followers. Journal of Applied Psychology, 95(6), 1134. http://psycnet.apa.org/doi/10.1037/a0020754

Wang, X.-H., \& Howell, J. M. (2012). A multilevel study of transformational leadership, identification, and follower outcomes. The Leadership Quarterly, 23(5), 775-790. http://dx.doi.org/10.1016/j.leaqua.2012.02.001 
Wu, J. B., Tsui, A. S., \& Kinicki, A. J. (2010). Consequences of differentiated leadership in groups. Academy of Management Journal, 53(1), 90-106. doi: 10.5465/AMJ.2010.48037079

Yammarino, F. J. (1990). Individual- and Group-Directed Leader Behavior Descriptions. Educational and psychological measurement, 50(4), 739-759. doi: 10.1177/0013164490504003

Yammarino, F. J., \& Bass, B. M. (1990). Transformational Leadership and Multiple Levels of Analysis. Human relations, 43(10), 975-995. doi: $10.1177 / 001872679004301003$

Yammarino, F. J., \& Dansereau, F. (2008). Multi-level nature of and multilevel approaches to leadership. The Leadership Quarterly, 19(2), 135-141.

Yammarino, F. J., Dionne, S. D., Uk Chun, J., \& Dansereau, F. (2005). Leadership and levels of analysis: A state-of-the-science review. The Leadership Quarterly, 16(6), 879-919. doi: http://dx.doi.org/10.1016/j.leaqua.2005.09.002

Yammarino, F. J., \& Dubinsky, A. J. (1994). Transformational leadership theory: Using levels of analysis to determine boundary conditions. Personnel Psychology, 47(4), 787-811. doi: http://dx.doi.org/10.1111/j.17446570.1994.tb01576.x

Zhang, Z., Zyphur, M. J., \& Preacher, K. J. (2009). Testing multilevel mediation using hierarchical linear models problems and solutions. Organizational Research Methods, 12(4), 695-719. 